\title{
Staged repair of pulmonary atresia with ventricular septal defect and major aortopulmonary collateral arteries: Experience with 104 patients
}

Anuja Gupta, $M D^{a}$

Jonah Odim, $M D^{\mathrm{b}}$

Daniel Levi, MD

Ruey-Kang Chang, MD, MPH

Hillel Laks, MD
From the Divisions of Pediatric Cardiolo$\mathrm{gy}^{\mathrm{a}}$ and Cardiothoracic Surgery, ${ }^{\mathrm{b}}$ UCLA Medical Center, Los Angeles, Calif.

Received for publication Jan 2, 2003; revisions requested Feb 21, 2003; revisions received May 8, 2003; accepted for publication June 18, 2003.

Address for reprints: Anuja Gupta, MD, 10621 Ashton Ave, Los Angeles, CA 90024 (E-mail: doctoranuja@yahoo.com).

J Thorac Cardiovasc Surg 2003;126: $1746-52$

Copyright $\odot 2003$ by The American Association for Thoracic Surgery

$0022-5223 / 2003 \$ 30.00+0$

doi:10.1016/S0022-5223(03)01200-5
Objective: To determine the early and intermediate-term outcome of the staged repair used to treat children with pulmonary atresia with ventricular septal defect and major aortopulmonary collateral arteries.

Methods: We reviewed a retrospective case series of 104 patients with this complex lesion. Information was obtained from medical records and referring physicians.

Results: Of the 104 patients treated with the staged repair, 58 achieved completion of anatomic repair. The 10 -year mortality was $16.5 \%$. In the patients with complete repair, the median right-to-left ventricle pressure ratio was 0.5 . The overall surgical reoperation rate was $17 \%$, and $15.5 \%$ of patients required postoperative interventional cardiac catheterization. In the multivariate analysis, the number of collateral vessels incorporated in the repair was found to be an independent risk factor for postoperative mortality and an elevated right-to-left ventricle pressure ratio after complete repair.

Conclusion: The staged repair can be successfully used to treat patients with pulmonary atresia with ventricular septal defect and major aortopulmonary collateral arteries. This method yields a relatively low mortality with good functional results.

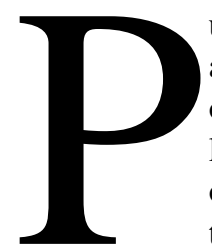

ulmonary atresia with ventricular septal defect (VSD) and major aortopulmonary collateral arteries (MAPCAs) is an uncommon form of complex congenital heart disease (Figure 1) ${ }^{1-3}$ Children with this lesion are treated using a staged repair at our institution. The objective of this study was to assess the early and intermediate term outcome of the staged repair in 104 pediatric patients with this disease. The main outcomes of interest were early and intermediate-term mortality, right-to-left ventricle pressure ratio (pRV/pLV) after complete repair, rate of surgical reoperation, requirement for postoperative interventional cardiac catheterization, and the functional status of survivors. We also sought to determine risk factors for unfavorable postoperative outcomes.

\section{Methods}

\section{Study Design and Patients}

The study design was a retrospective case series involving chart review and questionnaire or telephone contact with referring physicians. Between January 1983 and December 2000, 104 consecutive children with pulmonary atresia with VSD and MAPCAs were treated at our institution using the staged repair. All patients who presented with this diagnosis were treated and no patient was refused treatment. One patient who was diagnosed at birth died at 2 weeks of age prior to any intervention. This patient was excluded in the multivariate analysis. 

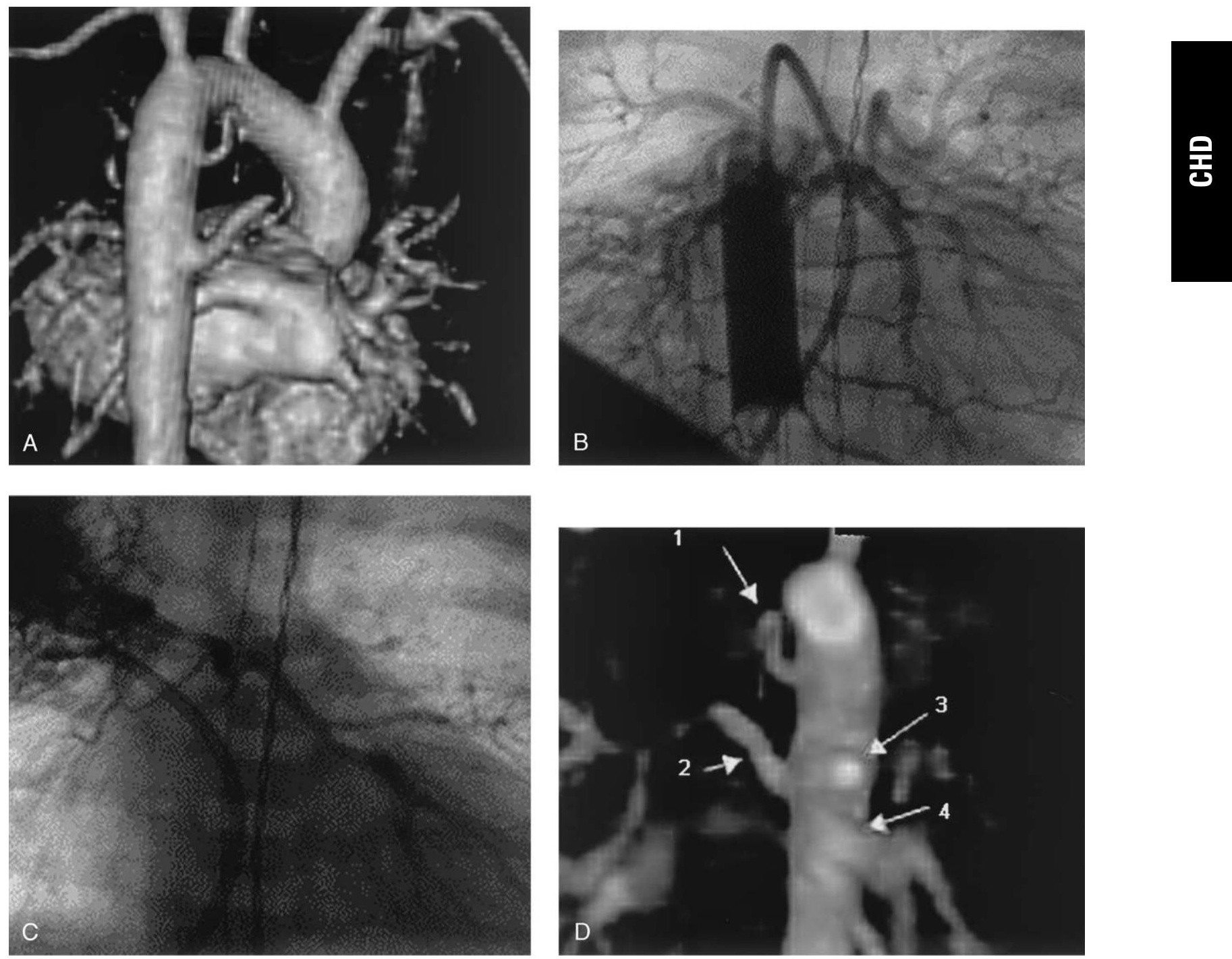

Figure 1. Pulmonary vascular supply in 2 patients with pulmonary atresia with ventricular septal defect and major aortopulmonary collateral arteries (MAPCAs). A, Magnetic resonance angiogram demonstrating absence of pulmonary arteries in the mediastinum. B, Descending aortic angiogram in the same patient demonstrating MAPCA distribution to all lung segments. C, Pulmonary venous wedge angiogram demonstrating a hypoplastic pulmonary artery. D, Magnetic resonance angiogram in the same patient demonstrating MAPCAs.

\section{Follow-up}

Follow-up of all patients was performed through December 2000. The median length of follow-up was 10.2 years.

\section{Procedure}

Details of the staged approach surgical repair and the management strategy the staged approach used at our institution have been previously described. ${ }^{4,5}$ In brief, our staged repair consists of 3 sequential steps (see Figure 2): Stage 1 involves palliative interventions (surgical or cardiac catheterization) to promote growth of the true pulmonary arteries when present and/or to control excessive pulmonary blood flow in cases with congestive heart failure. Stage 2 involves unifocalization of MAPCAs in both lungs. Stage
3 involves completion of the anatomic repair with closure of the VSD and establishment of continuity between the right ventricle and the reconstructed pulmonary vasculature.

\section{Outcome Measures}

The variables selected for assessment of outcome were early (in-hospital) and intermediate-term (10-year) mortality, pRV/pLV after complete repair, rate of surgical reoperation, requirement for postoperative interventional cardiac catheterization, and the functional status of the survivors. The $\mathrm{pRV} / \mathrm{pLV}$ was measured directly in the operating room after complete repair. The $\mathrm{pRV} / \mathrm{pLV}$ was also determined indirectly, during postoperative follow-up by using tricuspid valve regurgitation velocity on echocardiography as 


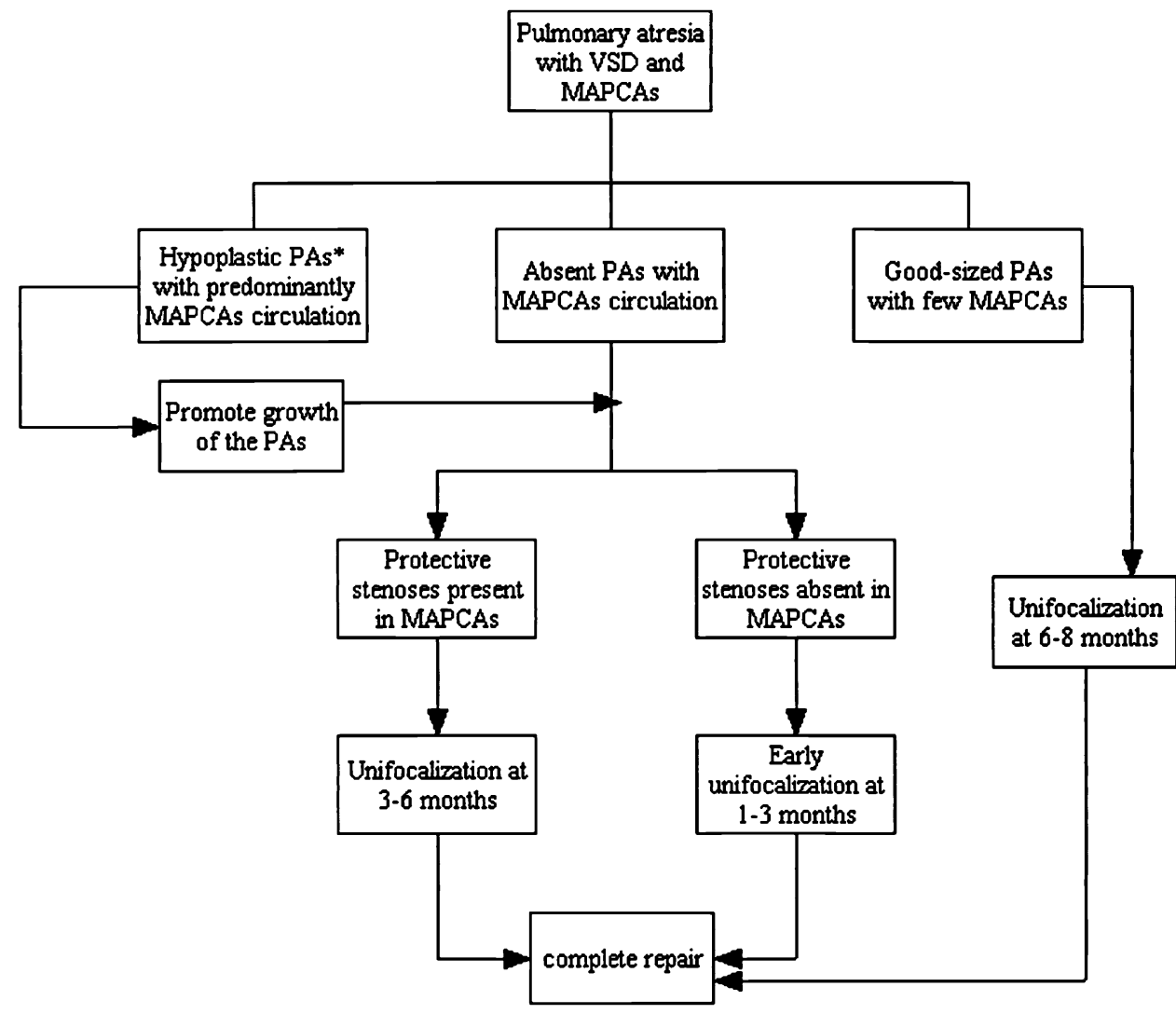

Figure 2. Management algorithm for patients with pulmonary atresia with ventricular septal defect (VSD) and major aortopulmonary collateral arteries (MAPCAs) based on the nature of pulmonary vascular supply.

TABLE 1. Characteristics of pulmonary vasculature in 104 patients with pulmonary atresia with VSD and MAPCAs

\begin{tabular}{|c|c|c|c|}
\hline $\begin{array}{l}\text { Type of pulmonary } \\
\text { vasculature }\end{array}$ & 1 & 2 & 3 \\
\hline $\begin{array}{l}\text { Predominant source } \\
\text { of pulmonary } \\
\text { circulation }\end{array}$ & MAPCAs & $\begin{array}{c}\text { Codominant } \\
\text { MAPCAs } \\
\text { plus PAs }\end{array}$ & PAs \\
\hline Pulmonary arteries & Absent & Hypoplastic & Good-sized \\
\hline $\begin{array}{l}\text { Pulmonary artery } \\
\text { size }^{*}\end{array}$ & - & $2 \mathrm{~mm}(1-3)$ & $4 \mathrm{~mm}(3-6)$ \\
\hline No. patients $(n=104)$ & 22 & 51 & 31 \\
\hline MAPCAs/patient* & $3(1-6)$ & $3(1-6)$ & $2(1-3)$ \\
\hline
\end{tabular}

VSD, Ventricular septal defect; MAPCAs, major aortopulmonary collateral arteries; $P A$, pulmonary artery.

${ }^{*}$ Median (range).

an estimate of the right ventricular pressure, and directly, by cardiac catheterization in the patients who required interventional cardiac catheterization after stage 3 repair.

Data Analysis

After review of the data, we performed descriptive and adjusted analysis. The descriptive analysis includes patient characteristics, pulmonary vasculature characteristics, overall and stagewise mortality, $\mathrm{pRV} / \mathrm{pLV}$ achieved after complete repair, surgical reoperation rate, and requirement for postoperative interventional cardiac catheterization. In the adjusted analysis risk factors for prediction of unfavorable outcomes (mortality and an elevated $\mathrm{pRV} / \mathrm{pLV}>$ $0.55)$ were determined. The independent variables of interest included several patient demographic and surgical factors. We performed multivariate logistic regression to identify these risk factors. The acceptable level of significance used was $P<.05$, and all the statistical analysis was performed using the STATA statistical software package.

\section{Results}

One hundred four consecutive patients (55 girls and 49 boys) with pulmonary atresia with VSD and MAPCAs were included in the series. Table 1 describes the characteristics of the pulmonary vasculature in the 104 patients. Seventeen $(16.5 \%)$ patients had associated intra- and extracardiac malformations that were repaired at the time of stage 3 surgery. Table 2 describes the patient characteristics and the associated cardiac malformations. Figure 3 shows the distribution of patients in each stage of the repair. 


\section{Stage 1}

Sixty-three of the 104 patients $(61 \%)$ underwent stage 1 repair. Patients in this group presented with either unacceptable cyanosis or intractable congestive heart in the early neonatal period. Table 3 shows the palliative surgical and interventional cardiac catheterization procedures used in stage 1 . The median age at stage 1 repair was 1 week (range 3 days to 22 years). After stage 1, $52(82.5 \%)$ patients progressed to stage 2 and $7(11 \%)$ patients are currently awaiting stage 2 . Four $(6 \%)$ deaths occurred in stage 1 repair.

\section{Stage 2}

A total of 92 patients underwent stage 2 repair (52 after stage 1 and 40 without stage 1 ). The 40 patients who did not require stage 1 repair prior to stage 2 included patients who remained clinically stable in early infancy with acceptable cyanosis and no significant congestive heart failure. The median age at stage 2 was 4.4 months (range 1 month to 37 years) Of the 92 patients treated, 54 (59\%) required bilateral unifocalization and $38(41 \%)$ required unilateral unifocalization. In patients who required bilateral unifocalization, the median time interval between surgery on the right and left lung was 1 year (range 3 months -5 years). The median number of MAPCAs unifocalized in stage 2 repair was 3 (range 1-6). After stage 2, 58 (63\%) patients progressed to stage 3 and 24 (26\%) patients are currently awaiting stage 3 . One patient was deemed inoperable for stage 3 repair because of prohibitively elevated pulmonary vascular resistance. Eight $(9 \%)$ deaths occurred in stage 2 repair.

\section{Stage 3}

A total of 58 patients underwent stage 3 repair. The median age at stage 3 repair was 5.2 years (range 1-34 years). The median time interval between stage 2 and stage 3 repair was 1.95 years (range 1-8.6 years). The median cardiac bypass time during stage 3 surgery was 168 minutes (range 114255 minutes). The median aortic crossclamp time was 114 minutes (range 47-190 minutes). The cardiac bypass time and aortic crossclamp time included repair of the associated cardiac malformations.

Of the 58 patients who achieved complete repair, 27 $(46 \%)$ originally had hypoplastic pulmonary arteries with codominant MAPCA circulation, 22 (38\%) had good-sized pulmonary artery with a dominant $(>60 \%)$ pulmonary artery circulation, and $9(15.5 \%)$ had absent true pulmonary arteries with a dominant MAPCA pulmonary circulation. Two (3\%) patients required creation of an adjustable atrial septal defect or fenestration of the VSD for $\mathrm{pRV} / \mathrm{pLV}>$ 0.75 . Five $(8.5 \%)$ deaths occurred in stage 3 repair.

\section{Mortality}

Figure 1 demonstrates the timing of deaths in relation to the surgical stage of repair. Excluding 1 patient who died prior
TABLE 2. Patient characteristics and associated cardiac malformations in 104 patients with pulmonary atresia with VSD and MAPCAs

\begin{tabular}{ll}
\hline $\begin{array}{l}\text { Gender ( } \mathrm{n}=104) \\
\text { Girls, no. (\%) }\end{array}$ & $55(53 \%)$ \\
Age at each stage of & \\
repair, median (range) & 1 week (3 days to 22 years) \\
Stage 1 & 4.4 months (1 month to 37 years) \\
Stage 2 & 5.2 years (1-34 years) \\
Stage 3 & \\
Associated cardiac & \\
malformations ( $\mathrm{n}=17)$ & 11 \\
Aortic insufficiency & 2 \\
Mitral insufficiency & 2 \\
Partial anomalous & \\
pulmonary venous & \\
repair & \\
Intramural left & 1 \\
coronary artery & \\
Coarctation of aorta & 1 \\
Patent foramen ovale & 14 \\
\hline
\end{tabular}

VSD, Ventricular septal defect; MAPCAs, major aortopulmonary collateral arteries.

to any intervention, there were a total of 17 deaths in the series and the overall 10 -year mortality was $16.5 \%$. The in-hospital (same surgical admission) mortality was $11.5 \%$ (12 deaths) and the late (after hospital discharge) mortality was $5 \%$ (5 deaths). The mortality rate in stage 1 repair was $6 \%, 9 \%$ in stage 2 , and $8.5 \%$ in stage 3 .

Of the 12 in-hospital deaths, 2 occurred during interventional cardiac catheterization after stage 1 repair, 2 resulted from hypoxia induced by bronchospasm, 3 from suprasystemic $\mathrm{pRV} / \mathrm{pLV}, 2$ from bacterial sepsis, 1 from hypoxia induced by clotted unifocalization shunt, and 2 from unknown causes. Of the 5 late deaths, 1 resulted from liver failure in a patient with associated Alagilles syndrome, 1 from suprasystemic $\mathrm{pRV} / \mathrm{pLV}, 1$ from hypoxia induced by clotted unifocalization shunt, 1 from hypoxia induced by pulmonary embolism, and 1 from unknown cause.

\section{Morbidity}

The median $\mathrm{pRV} / \mathrm{pLV}$ obtained in the operating room immediately after complete repair was 0.5 (range 0.15-1.0). The median $\mathrm{pRV} / \mathrm{pLV}$ estimated at follow-up visits by echocardiography as described in the Methods section was 0.46 (range $0.3-1.0$ ). The median $\mathrm{pRV} / \mathrm{pLV}$ measured by cardiac catheterization was 0.55 (range 0.35-1.0).

There were a total of $36(17 \%)$ reoperations in the series. The reoperation rate for stage 1 repair was $16 \%$ (10 procedures). The indications for reoperation after stage 1 included excessive cyanosis or intractable congestive heart failure from excessive pulmonary blood flow. The reoperation rate for stage 2 repair was $19.5 \%$ (18 procedures). The most 


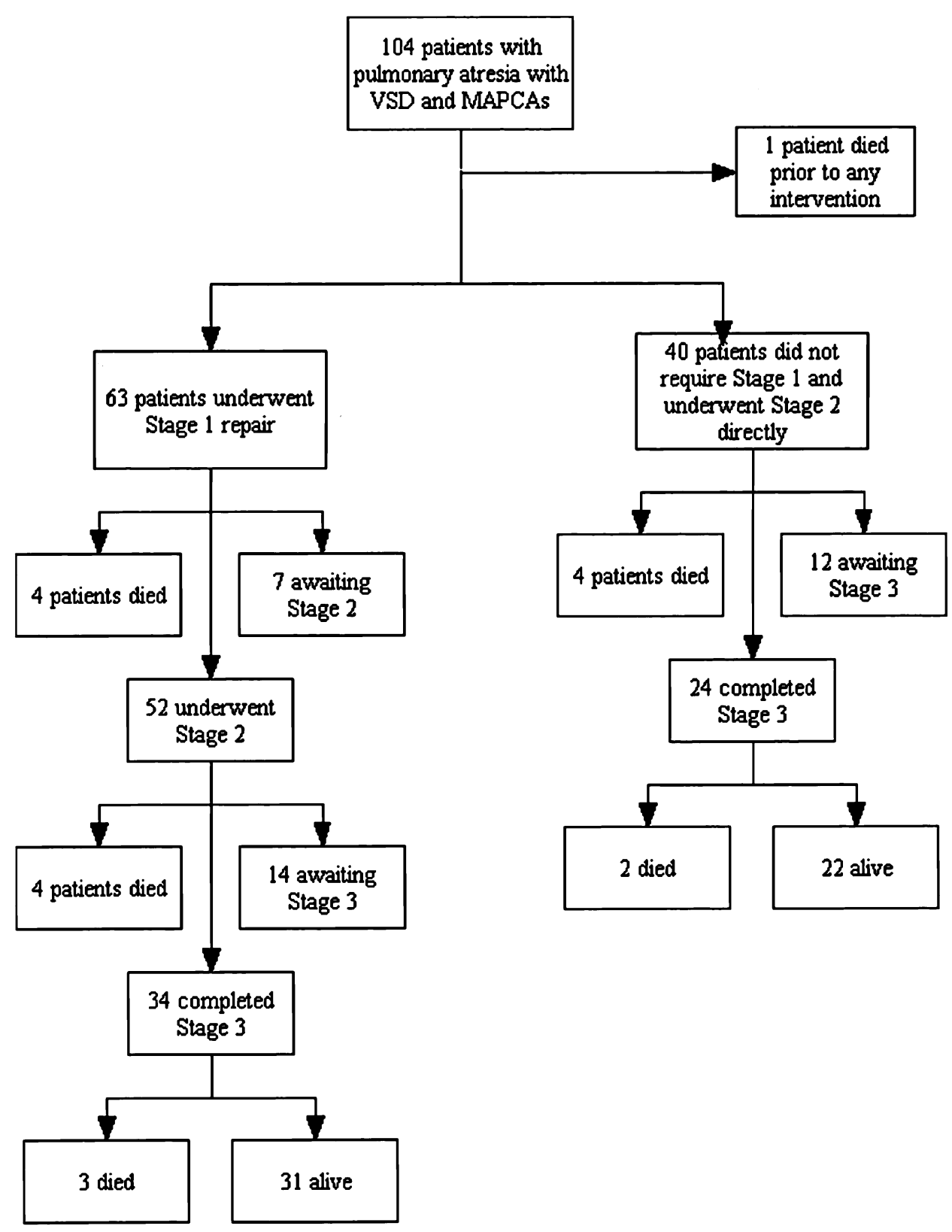

Figure 3. Distribution of 104 patients with pulmonary atresia with ventricular septal defect and major aortopulmonary collateral arteries in the staged repair.

common indication for reoperation after stage 2 was excessive cyanosis secondary to thrombosis or stenosis of the unifocalization shunt. The reoperation rate for stage 3 repair was $14 \%$ ( 8 procedures). The indication for reoperation after stage 3 was $\mathrm{pRV} / \mathrm{pLV}>0.75$ from stenosis of the right ventricle to pulmonary artery homograft conduit.

Postoperatively there were 16 interventional cardiac catheterization procedures in the entire group. This does not include the catheterization interventions performed for stage 1 repair. Of the interventions, $15 \%$ occurred after stage 1 , $70 \%$ after stage 2 , and $15 \%$ after stage 3 repair. The lesions treated by interventional cardiac catheterization included: branch pulmonary artery stenosis in 9 patients $(5$ responded favorably to balloon angioplasty and 4 required stent placement in stenosis sites); MAPCAs stenosis in 5 patients (3 responded to balloon angioplasty and 2 required stent place- 
ment and unifocalization tube); stenosis in 2 patients (1 responded to balloon angioplasty and 1 required stent placement) in the unifocalization tube.

The functional status of survivors was defined qualitatively by the New York Heart Association (NYHA) classification. Of the 53 survivors after complete repair, 47 (89\%) were in NYHA class I or II and were either full-time students, were employed full-time, or were capable of fulltime work. Six (11\%) patients were judged to be in NYHA class III or IV with significant symptoms. The symptoms that these patients were experiencing included recurrent and refractory ventricular tachycardia or congestive heart failure due to deterioration of right ventricular function.

\section{Results of Multivariate Analysis}

In the univariate analysis the number of MAPCAs included in the unifocalization was found to significantly predict the risk of death and of an elevated $\mathrm{pRV} / \mathrm{pLV}>0.55$ postoperatively. Patients with fewer than 3 MAPCAs included in the repair were at higher risk for both unfavorable outcomes when compared with those with more than 3 MAPCAs $(P<$ $.05)$. In the univariate analysis, independent factors such as age and weight at first surgery, age at last surgery, sex of patient, distribution of native pulmonary arteries, and surgical variables such as duration of cardiac bypass time and aortic crossclamp time were not found to be significant predictors of mortality or of an elevated $\mathrm{pRV} / \mathrm{pLV}$. Because of the small number of patients in each subgroup, meaning comparison using multivariate analysis became difficult.

\section{Discussion}

This study reports our experience with the staged repair used in the treatment of children with pulmonary atresia with VSD and MAPCAs. We evaluated the early and intermediate-term outcome of the staged repair by measuring mortality, $\mathrm{pRV} / \mathrm{pLV}$ after complete repair, surgical reoperation rate, requirement for postoperative interventional catheterization, and the functional status of survivors. In 104 patients with this complex lesion, the overall in-hospital mortality was $11.5 \%$ and the overall 10 -year mortality was $16.5 \%$. The median $\mathrm{pRV} / \mathrm{pLV}$ ratio after complete repair was 0.5 . The surgical reoperation rate was $17 \%$, and only 16 procedures for interventional cardiac catheterization were required postoperatively. Most survivors after complete repair were in NYHA class I or II symptomatically.

The overall mortality rate observed in our series is comparable to that noted in previous studies. ${ }^{6-20}$ The $\mathrm{pRV} / \mathrm{pLV}$ is widely regarded as a surrogate measure of functional status after complete anatomic repair of this lesion. The $\mathrm{pRV} / \mathrm{pLV}$ observed in our study is also comparable to that reported in other large series. ${ }^{6-20} \mathrm{We}$ believe that this favorable $\mathrm{pRV} / \mathrm{pLV}$, particularly in patients who had extremely hypoplastic true pulmonary arteries with relatively
TABLE 3. Palliative surgical and interventional cardiac catheterization interventions performed in stage 1 repair

\begin{tabular}{|c|c|}
\hline Type of stage 1 intervention & $\begin{array}{c}\text { No. of } \\
\text { patients } \\
(n=63)\end{array}$ \\
\hline \multirow{3}{*}{\multicolumn{2}{|c|}{$\begin{array}{l}\text { 1. Intervention to increase } \\
\text { pulmonary blood flow } \\
\text { a. Surgical }(\mathrm{n}=50)\end{array}$}} \\
\hline & \\
\hline & \\
\hline Aortopulmonary artery shunt & 40 \\
\hline $\begin{array}{l}\text { Right ventricle outflow tract } \\
\text { patch }\end{array}$ & 7 \\
\hline $\begin{array}{l}\text { Right ventricle to pulmonary } \\
\text { artery conduit }\end{array}$ & 2 \\
\hline Pulmonary artery & 1 \\
\hline \multicolumn{2}{|l|}{ b. Cardiac catheterization ( $\mathrm{n}=8$ ) } \\
\hline Pulmonary valvuloplasty & 4 \\
\hline $\begin{array}{l}\text { Right ventricle outflow tract } \\
\text { stent }\end{array}$ & 3 \\
\hline Collateral stenting & 1 \\
\hline \multirow{2}{*}{\multicolumn{2}{|c|}{$\begin{array}{l}\text { 2. Intervention to reduce pulmonary } \\
\text { blood flow } \\
\text { a. Surgical }(n=14)\end{array}$}} \\
\hline & \\
\hline $\begin{array}{l}\text { Collateral banding with } \\
\text { aortopulmonary artery } \\
\text { shunt }\end{array}$ & 11 \\
\hline $\begin{array}{l}\text { Collateral banding alone } \\
\text { b. Cardiac catheterization }(n=1)\end{array}$ & 3 \\
\hline Collateral embolization & 1 \\
\hline
\end{tabular}

few MAPCAs, is the result of the aggressive approach used to encourage growth of the true pulmonary arteries and aggressive recruitment of as many MAPCAs as possible in the repair, resulting in a larger effective pulmonary vasculature. In the univariate analysis we found that unifocalization of fewer than 3 MAPCAs in the repair was significantly associated with an increased likelihood of mortality and $\mathrm{pRV} / \mathrm{pLV}>0.55(P<.05)$.

The overall surgical reoperation rate noted in our study was $16 \%$, which is slightly higher than that previously reported. ${ }^{6,7,15-18}$ There are several possible explanations for this. Because stages 1 and 2 of the repair are performed in early infancy, the physiologic requirements of the patient frequently change with growth. The most common indication for reoperation in after stages 1 and 2 was excessive cyanosis in patients who had previously acceptable oxygen saturations after surgery. These patient required reoperation with insertion of larger unifocalization shunts. Another indication for reoperation was pulmonary artery reconstruction in patients who did not respond favorably to interventional catheterization procedures.

Several patients with extremely hypoplastic pulmonary arteries required multiple surgeries to be successfully salvaged. Remarkably, no reoperations were required for stenosis in MAPCAs, all cases of which responded favorably 
to interventional cardiac catheterization techniques. Also, very few reoperations were required after complete repair. We believe this to be the result of the relatively late age of stage 3 repair, which enables the use of larger-sized conduits thus reducing the requirement for subsequent revision.

The requirement for postoperative interventional cardiac catheterization in our series was relatively low, only 16 procedures in the entire series. In our opinion, this is the result of staging the repair in patients with this lesion. The use of the lateral thoracotomy incision for performing the unifocalization procedure not only provides excellent exposure of the MAPCAs but also enable greater flexibility in recruiting them into the repair. This results in reduced torsion at the surgical anastomosis sites with a lower rate of subsequent stenosis.

The limitations of this study include a relatively limited follow-up period (median follow-up 10 years) and lack of generalizability of results to all patients with pulmonary atresia with VSD and MAPCAs. Follow-up of survivors from this series is ongoing and longer follow-up data will be available in the future. Because all patients in this study were treated with the staged approach, direct comparison with patients treated with the single-staged approach is difficult. For meaningful comparison between these 2 approaches, randomized allocation of patients with pulmonary atresia with VSD and MAPCAs to single-staged or staged repair would be required.

In summary, the results of our study indicate that children with pulmonary atresia with VSD and MAPCAs can be successfully treated using the staged repair. In our experience the staged repair yields a relatively low mortality with good functional results. There remains room for improvement in the requirement for surgical reoperation. As our experience with this approach has evolved, we have observed a significant reduction in the associated mortality and morbidity. We anticipate an improved quality of life with reduced need for postoperative surgical and interventional catheterization in patients treated with this approach in the future.

\section{References}

1. Jefferson K, Rees S, Somerville J. Systemic arterial supply to the lungs in pulmonary atresia and its relation to pulmonary artery development. Br Heart J. 1972;34:418-27.

2. Haworth SG, Macartney FJ. Growth and development of pulmonary circulation in atresia with ventricular septal defect and major aortopulmonary collateral arteries. Br Heart J. 1980;44:14-24.

3. Liao P, Edwards WD, Julsrud PR, Puga FJ, Danielson GK, Feldt RH. Pulmonary blood supply in patients with pulmonary atresia and ventricular septal defect. J Am Coll Cardiol. 1985;6:1343-50.

4. Permut LC, Laks H. Surgical management of pulmonary atresia with ventricular septal defect and multiple aortopulmonary collaterals. $A d v$ Card Surg. 1994;5:75-95.

5. Permut LC, Laks H. Surgical management of pulmonary atresia with ventricular septal defect. Glenn's Thoracic and Cardiovascular Surgery. 1996;2:1333-45.

6. Iyer KS, Mee RB. Staged repair of pulmonary atresia with ventricular septal defect and major systemic to pulmonary artery collaterals. Ann Thorac Surg. 1991;51:65-72.

7. Puga FJ, Lconi FE, Julsrud PR, Mair DD. Complete repair of pulmonary atresia, ventricular septal defect, and severe peripheral arborization abnormalities of the central pulmonary arteries: experience with preliminary unifocalization procedures in 38 patients. J Thorac Cardiovasc Surg. 1989;98:1018-29.

8. Yagihara T, Yamamoto F, Nishigaki K, et al. Unifocalization for pulmonary atresia with ventricular septal defect and major aortopulmonary collateral arteries. J Thorac Cardiovasc Surg. 1996;112:392402.

9. Sullivan IDS, Wren C, Stark J, de Leval M, Macartney FJ, Deanfield JE. Surgical unifocalization in pulmonary atresia and ventricular septal defect: a realistic goal? Circulation. 1988;78:III5-13.

10. Sawatari K, Imai Y, Kurosawa H, Isomatsu Y, Momma K. Staged operation for pulmonary atresia and ventricular septal defect with major aortopulmonary collateral arteries. New technique for complete unifocalization. J Thorac Cardiovasc Surg. 1989;98:738-50.

11. Hadjo A, Jimenez M, Baudet E, et al. Review of the long-term course of 52 patients with pulmonary atresia and ventricular septal defect. Anatomical and surgical considerations. Eur Heart J. 1995;16:166874.

12. Metras D, Chetaille P, Kreitmann B, Fraisse A, Ghez O, Riberi A. Pulmonary atresia with ventricular septal defect, extremely hypoplastic pulmonary arteries, major aorto-pulmonary collaterals. Eur J Cardiothorac Surg. 2001;20:596-7.

13. Dinaveric S, Redington A, Rigby M, Shinebourne EA. Outcome of pulmonary atresia and ventricular septal defect during infancy. Pediatr Cardiol. 1995;16:276-82.

14. Sawatari K, Imai Y, Kurosawa H, Isomatsu Y, Momma K. Staged operation for pulmonary atresia and ventricular septal defect with major aortopulmonary collateral arteries. New technique for complete unifocalization. J Thorac Cardiovasc Surg. 1989;98:738-50.

15. Reddy VM, McElhinney DB, Amin Z, et al. Early and intermediate outcomes after repair of pulmonary atresia with ventricular septal defect and major aortopulmonary collateral arteries: experience with 85 patients. Circulation. 2000;101:1826-32.

16. Murthy KS, Krishnanaik S, Coelho R, Punnoose A, Arumugam SB, Cherian KM. Median sternotomy single stage complete unifocalization for pulmonary atresia, major aorto-pulmonary collateral arteries and VSD—early experience. Eur J Cardiothorac Surg. 1999;16:21-5.

17. Tchervenkov CI, Salasidis G, Cecere R, et al. One-stage midline unifocalization and complete repair in infancy versus multiple-stage unifocalization followed by repair for complex heart disease with major aortopulmonary collaterals. J Thorac Cardiovasc Surg. 1997; 114:727-35.

18. Lofland GK. The management of pulmonary atresia, ventricular septal defect, and multiple aorta pulmonary collateral arteries by definitive single stage repair in early infancy. Eur J Cardiothorac Surg. 2000; 18:480-6.

19. Carotti A, Di Donato R, Squitieri C, Guccione P, Catena G. Total repair of pulmonary atresia with ventricular septal defect and major aortopulmonary collaterals: an integrated approach. $J$ Thorac Cardiovasc Surg. 1998;116:914-23.

20. Luciani GB, Winfield JW, Khong A, Starnes VA. The clamshell incision for bilateral pulmonary artery reconstruction in tetralogy of Fallot with pulmonary atresia. J Thorac Cardiovasc Surg. 1997;113: 443-52. 